\title{
O PAPEL DA ENTONAÇÃO E DA REPETIÇÃO NO FUNCIONAMENTO DA RASURA ORAL EM ESCRITA COLABORATIVA NA SALA DE AULA
}

\section{THE ROLE OF INTONATION AND REPETITION IN THE OPERATION OF ORAL RASURE IN A COLLABORATIVE WRINTING IN THE CLASSROOM}

\author{
Cristina Felipeto - UFAL/FALE/PPGLL ${ }^{1}$ \\ Míriam Pessôa Marques - UFAL 2
}

\begin{abstract}
RESUMO
O presente trabalho tem por objetivo compreender o funcionamento da rasura oral através da repetição e da entonação quando uma díade de alunas recém-alfabetizadas escreve em colaboração um único texto. Inserida no campo da Linguística Textual, a presente pesquisa se apoia nos estudos enunciativos propostos por Benveniste $(1991 ; 2006)$, pela relação dialógica em que se encontram as alunas, e na Genética Textual, que propõe a análise do processo de escritura e não apenas a do produto final. A Genética Textual traz conceitos essenciais para o trabalho, como os de rasura e manuscrito. O corpus utilizado faz parte do banco de dados Prática de Textualização na Escola (PTE), pertencente ao Laboratório do Manuscrito Escolar (L’ÂME), e é constituído pela filmagem, áudio, transcrição e produto final de cada processo, o manuscrito. Para a presente pesquisa, foram analisados processos de escritura, de uma díade de alunas com idade entre 7 e 8 anos, coletados nos anos de 1991 e 1992, durante o primeiro e segundo ano do Ensino Fundamental, respectivamente, em uma escola particular da cidade de São Paulo - SP. A partir da análise e discussão dos dados, pôde-se compreender um pouco mais do funcionamento da rasura oral, elemento inerente ao ato de escrita em pares e contribuir para os estudos da gênese textual, escrita colaborativa e da didática da escrita.
\end{abstract}

PALAVRAS-CHAVE : Rasura Oral. Escrita Colaborativa. Entonação. Repetição.

\begin{abstract}
The aim of the present work is to understand the operation of oral erasure through repetition and intonation when a dyad of newly literate students writes a single text. In the field of Textual Linguistics, this research is supported by the enunciative studies proposed by Benveniste (1991, 2006), by the dialogical relationship in which the students are found, and in Textual Genetics, which proposes the analysis of the writing process and not only of the final product. Textual Genetics brings concepts essential to the work, such as the erasure and manuscript. The corpus used is part of the Practical of Textualization in School (PTE) database, belonging to the Laboratory of the School Manuscript (L'ÂME), and consists of filming, audio, transcription and the final product of each process, the manuscript. For the present research, we analyzed the writing processes of a dyad of students aged 7 to 8 years, collected in 1991 and 1992, during the first and second year of elementary school, respectively, in a private school in the city of São Paulo - SP. From the analysis and discussion of the data, it was possible to understand a little more about the functioning of oral
\end{abstract}

${ }^{1}$ Doutora em Linguística. E-mail : crisfelipeto@gmail.com

${ }^{2}$ Mestre em Linguística. E-mail : miriam.pess.m@gmail.com 
erasure, an inherent element of the act of writing in pairs and to contribute to the studies of textual genesis, collaborative writing and didactic writing.

KEYWORDS: Oral Erasure. Collaborative Writing. Intonation. Repetition.

\section{INTRODUÇÃO}

O presente trabalho busca compreender o funcionamento da rasura oral, fato inerente e observável em processos de produção textual que ocorrem em situações de escrita colaborativa em sala de aula, por meio de dois elementos: a repetição e a entonação. Dito de outro modo, nosso objetivo é mostrar que, quando dois alunos escrevem juntos um único texto, alguns enunciados provocam determinadas atitudes responsivas (dúvidas, concordância, discordância, estímulo à negociação) que fazem com que os alunos se utilizem da repetição lexical, aliada a uma entonação expressiva, para retomar algo que foi dito anteriormente, pelo outro, e obter dele, interlocutor, determinado posicionamento. Essa repetição com entonação expressiva pode produzir rasuras orais, que alteram ou não aquilo que foi ou poderia ter sido escrito.

Para a presente pesquisa, foram analisados processos de escritura de uma díade de alunas com idade entre 7 e 8 anos (sujeitos $\mathrm{N}$ e I). Os dados que compõem o corpus foram coletados durante o primeiro e segundo anos do Ensino Fundamental, em uma escola particular da cidade de São Paulo - SP. As alunas combinaram e escreveram histórias inventadas e, alternadamente, uma ficava de posse da caneta, enquanto a outra acompanhava e ficava responsável por "lembrar" o que havia sido combinado. Todos os processos foram filmados e posteriormente transcritos.

Para a discussão, buscamos fundamento teórico na Genética Textual, por nos possibilitar um novo olhar sobre o texto, a partir do manuscrito e suas marcas, e na Linguística Enunciativa representada por Benveniste, por subsidiar e caracterizar a relação dialógica que se instaura em processos de escrita colaborativa.

\section{A gênese textual: uma possibilidade de análise do processo de produção textual}

As marcas deixadas pelo escritor possibilitam ao pesquisador uma compreensão acerca do que foi escrito. Desse modo, a rasura é uma das principais marcas deixadas no papel, já que ela oferece pistas importantes sobre as intenções do autor no momento da escritura. De acordo com Grésillon (2007), a rasura é

\footnotetext{
simultaneamente perda e ganho. Ela anula o que foi escrito, ao mesmo tempo em que aumenta o número de vestígios escritos. É nesse próprio paradoxo que repousa o interesse genético da rasura: seu gesto negativo transforma-se para o geneticista em tesouro de possibilidades, sua função de apagamento dá acesso ao que poderia ter-se tornado texto (p. 97).
}

Willemart (1993), corroborando com o pensamento de Grésillon, afirma que a rasura “assinala em primeiro lugar uma atitude negativa, um 'não gosto disso', uma impressão de falta ou de falha na escritura que empurra a mão para suprimir a escrita anterior por uma razão muitas vezes desconhecida pelo próprio escritor" (p. 156). Certamente que colaboram para este movimento questões gramaticais, estéticas e padrões exigidos pelo gênero textual em questão.

A partir dos elementos rasurados, pode-se ter uma noção dos caminhos que o autor percorreu para chegar até a finalização de seu texto. Isso não quer dizer que através dos manuscritos e de suas rasuras, os pensamentos são acessados de alguma maneira, pois ainda inexiste ferramenta com tal capacidade. Porém, as rasuras funcionam como "pegadas» que permitem ao investigador 
compreender mudanças de rumo, alterações semânticas, produções de erros, etc., que sem elas não poderiam ser compreendidos, mostrando as especificidades da gênese textual.

De acordo com Biasi (2010), a rasura é um componente da escritura que apesenta certa complexidade, embora seja ignorada pelos professores (na maioria das vezes) e tratadas como algo sujo que precisa de apagado, jogado fora. Para Calil (2012), a rasura apresenta uma propriedade reflexiva, indicada por um retorno ao texto. A rasura, reconhecida como operação metalinguística, traz em seu bojo uma ação do escrevente sobre o que foi escrito, marcando o reconhecimento de uma diferença entre o que estava escrito e a inscrição de um novo elemento que ocupa alguma posição na cadeia sintagmática.

\footnotetext{
Em poucas palavras, o processo de escritura e o manuscrito que é seu produto compõem um sistema semiótico multimodal no qual a rasura marca os pontos de tensão no fluxo da escritura, manifestando um retorno visível que indicia as relações dialógicas. A rasura seria, portanto, um efeito do acaso do processo de escritura, sendo imprevisível em que ponto do texto em curso irá manifestar-se (CALIL, 2012, p. 593).
}

Ter acesso a um manuscrito de uma escrita individual, silenciosa, possibilita ao investigador uma compreensão reduzida acerca das pretensões do autor durante o processo de escritura através das marcas deixadas no papel, porém, quando a escrita deixa de ser individual e passa a ser realizada em díades, as possibilidades são maiores, pois, durante a discussão sobre o que escrever, a dupla interage e deixa emergir questões que antes seriam inacessíveis. Desse modo, o pesquisador tem em mãos os instrumentos necessários para a realização de uma análise mais fidedigna e pode demonstrar que o processo de escritura é árduo e carrega uma série de singularidades e complexidades que, até antes desses estudos, passavam despercebidos.

Assim, a Genética Textual contribui para o estudo daqueles que estão interessados mais no processo de escrita de um texto, do que no seu produto final, o texto acabado. Nessa direção, a relação com a Genética textual faz com que a investigação sobre o processo de escrever esteja suscetível à evolução tão logo se insista no aspecto sempre ativo e, muitas vezes, imprevisível que acompanha a escritura. Quando se trata de um processo de escritura a dois, em que a situação é capturada em tempo real, as rasuras não se limitam à folha de papel, elas também ocorrem na oralidade.

A rasura oral, conceito elaborado por Calil (2016), busca dar conta da situação específica de se falar para escrever em contexto escolar e caracteriza-se por retornos ocorridos oralmente, durante o fluxo dialogal, ao incidir sobre o que foi, será ou não inscrito e linearizado. Ela indica o modo espontâneo e imprevisível com que cada aluno altera ou modifica elementos a serem escritos no manuscrito em curso. Desta forma, o registro de rasuras orais mapeia a gênese do processo de escritura a dois.

\section{A enunciação: componente inerente à escritura compartilhada}

O formato de escrita colaborativa se reveste de uma importância fundamental para a prática de produção textual em sala de aula, posto que instaura uma situação discursiva propícia à interação e conhecimentos para compartilhar. Mas, de um ponto de vista estritamente linguístico, enunciativo, como se constitui e como se caracteriza o diálogo, base de situações de escrita colaborativa? Os trabalhos realizados por Benveniste $(1991 ; 2006)$ nos fornecem subsídios interessantes para compreendermos a situação didática dialográfica ${ }^{3}$ em que se encontram os alunos (juntos discutindo e escrevendo um mesmo texto), as trocas de posição, as tentativas de influenciar um ao outro, os questionamentos, etc.

${ }^{3}$ A palavra dialográfica, proposta por Gaulmyn (2001), corresponde ao ato de falar para escrever, ação que é a base da escrita colaborativa. 
Para este autor, a subjetividade é "a capacidade do locutor para se propor como sujeito" (BENVENISTE, 1991, p. 286) através de formas que toda língua possui, como os pronomes pessoais, os indicadores da dêixis e alguns verbos. Assim, "eu" designa aquele que fala e que, por se dirigir a alguém, constitui, ao mesmo tempo, um "tu". Essa é a condição básica do diálogo e tem como característica a reciprocidade: "que eu me torne tu na alocução daquele que por sua vez se designa por eu" (op. cit, p. 286). Essa polaridade e indissociabilidade das pessoas "eu" e "tu" são condições fundamentais para a existência da intersubjetividade e é o que torna possível toda comunicação linguística.

Já o "ele" encontra-se ausente desta relação constitutiva entre "eu" e "tu", já que, para Benveniste, trata-se de uma não-pessoa. A terceira pessoa é uma forma verbal que tem como finalidade exprimir a não-pessoa e comporta, assim, uma indicação de enunciado sobre algo - aquilo de que se fala ou aquele de que se fala. No caso da escrita colaborativa em sala de aula, trata-se do objeto textual em questão. Assim, é pelo vazio enunciativo deixado pelo "tu" que o "eu" ocupa espaço na enunciação e presentifica o "ele", instituindo o mundo pelo discurso. Essa possibilidade de "eu" e "tu" inverterem-se constantemente no tempo e instanciarem pelo discurso a não pessoa "ele" respalda a condição de diálogo que se instaura em situações de escrita colaborativa da qual participam díades.

Ao definir o que é o Plano do discurso, Benveniste diz tratar-se de:

Toda enunciação que suponha um locutor e um ouvinte e, no primeiro, a intenção de influenciar, de algum modo, o outro. [...] enfim, todos os gêneros nos quais alguém se dirige a alguém, se enuncia como locutor e organiza aquilo que diz na categoria de pessoa (p. 267).

Como se vê, a intersubjetividade é inerente à escritura compartilhada e face-a-face. São esses movimentos na estrutura enunciativa propiciados por situações de escritura colaborativa que re(criam) e transmitem regras relacionadas à criação e composição textual.

Durante o processo de discussão sobre o que escrever (o que vai para o papel), os alunos acabam se apropriando de determinados artifícios linguísticos com a intenção de causar um efeito no outro. Em nossa investigação, esse fenômeno pode ser percebido através da repetição e da entonação, elementos investigados no processo de funcionamento da rasura oral.

\section{Repetição e entonação: fenômenos inerentes ao processo de escrita colaborativa}

A partir de análises de processos de escrita colaborativa, observou-se que algumas rasuras orais surgiam a partir da interferência de dois fenômenos, a repetição e a entonação. Estes dois elementos juntos eram capazes provocar atitudes e tomadas de decisão no interlocutor, inserido no processo de composição textual, capazes de alterar o percurso do texto de forma quase que "instantânea". Por fazerem parte da interação conversacional, não é surpreendente que esses fenômenos surjam durante o processo de escritura, porém, o fato deles alterarem o percurso do texto, provocando apagamentos significativos, não pode ser ignorado, pelo contrário, visto que eles auxiliam na compreensão do funcionamento da rasura oral, componente inerente da escrita a dois. Por fazer parte do planejamento da fala, a repetição é um processo recorrente na oralidade. Diferente do texto escrito, em que a repetição é vista de forma negativa, no texto oral ela está presente e faz parte do processo de formulação. Marcuschi (2015) aponta que, enquanto na oralidade as repetições levam à produção de segmentos completos duas ou mais vezes, na escrita, os processos de revisão e editoração culminam na diminuição de repetições no produto final. Ainda de acordo com o autor, entre os processos de formulação textual presentes na língua falada, a repetição é um dos mais utilizados. De acordo com Koch (2002), a repetição é uma estratégia essencial de estruturação da fala que possibilita a absorção do novo como algo conhecido. 
Corroborando com a autora, Tannen (2007) argumenta que a repetição é composta por uma série de padrões que contribuem para a coerência no discurso, pois ela permite que o falante se expresse de forma mais coerente, facilitando a compreensão e fornecendo um discurso menos denso. Por se tratar de um elemento que está muito presente na oralidade, é interessante apontar que há diversos tipos de repetições que são capazes de provocar os mais variados efeitos no interlocutor (DESHAIES, PARADIS \& PERRIN, 2003; TANNEN, 2007).

Deshaies, Paradis \& Perrin (2003), em seu trabalho sobre repetição diafônica, apontam alguns tipos de repetições, ressaltando que elas podem se referir a um enunciando do falante, do interlocutor ou de um terceiro. Sendo assim, os autores apontam que existem repetições autofônicas (quando o próprio locutor repete seu discurso) ou diafônicas (quando o discurso repetido é o do interlocutor) e heterofônicas. Estas últimas se referem ao fato de que o falante repete, muitas vezes, enunciados que podem ter sido proferidos no momento da interação conversacional, com os participantes presentes, ou não, e esse fato não é relevante. Já as repetições autofônica ou diafônica têm como fato relevante o momento do acontecimento, os interactantes estão presentes e a repetição ocorre logo após o primeiro enunciado ser proferido. Para o presente estudo, a repetição diafônica é a que melhor se enquadra nos dados analisados, uma vez que durante o processo de composição do texto, alguns enunciados provocam determinadas atitudes (insatisfação, dúvida, etc.) que fazem com que os alunos se utilizem da repetição para obter do outro, interlocutor, determinado posicionamento. Assim, como estratégia, os alunos não repetem seus próprios enunciados, mas os enunciados do outro.

Marcuschi (2015), ao tratar das funcionalidades das repetições, afirma que elas se manifestam de várias formas e são multifuncionais. No que se refere à produção "os segmentos repetidos podem distribuir-se entre autorrepetições e heterorrepetições, sendo estas menos frequentes" (MARCUSCHI, 2015, p. 210). Assim, semelhante às repetições autofônicas, as autorrepetições ocorrem quando o falante repete elementos da sua própria fala, já as heterorrepetições ocorrem quando o interlocutor repete elementos presentes na fala do locutor, semelhante às repetições diafônicas.

Desse modo, Deshaies, Paradis \& Perrin (2003) apontam que durante o processo de interação conversacional é possível observar que um interlocutor comumente repete as palavras do outro com um interesse pessoal. Isso porque repetir não significa, de forma alguma, dizer a mesma coisa. Não se repete pelo simples ato de repetir, a repetição expressa algo novo, ela apresenta uma intencionalidade, não sendo, assim, tautológica (KOCH, 2002; MARCUSCHI, 2015; TANNEN, 2007).

Os alunos, durante o processo de escritura, repetem comumente as palavras ou frases do outro, repetição lexical, para demonstrar seu posicionamento em relação ao que foi proferido sobre a composição do texto, resultando, assim, em apagamentos ao longo da composição textual. Porém, é interessante ressaltar que, após as análises, observou-se que a repetição isolada não é capaz de causar efeito no outro, a entonação também está presente nesse processo.

A entonação faz parte dos estudos da prosódia, campo amplo e complexo que, assim como outras áreas da linguística, sofre certo preconceito por tratar, principalmente, daquilo que foge do domínio lexical. No entanto, a importância de se debruçar sobre esses estudos está no fato de fenômenos como a entonação estarem presentes e influenciarem os atos enunciativos. No caso específico deste trabalho, em que os alunos discutem de forma colaborativa sobre o que escrever, a entonação, assim como a repetição, exerce um papel importante para a compreensão da rasura oral, visto que não é apenas o fato de os alunos repetirem que instiga um posicionamento do outro, mas o fato de eles repetirem com uma entonação expressiva.

Segue o exemplo abaixo, retirado do corpus. Neste fragmento, Nara e Isabel estão escrevendo a história inventada "Os treis todinhos e a dona sabor" 4

${ }^{4} \mathrm{O}$ título original foi mantido.

Revista do GELNE, Natal/RN, Vol. 20 - Número 1: p. 74-86. 2018 
425 ISABEL: "...a mãe... a mãe... (flexionando a voz) tava tãão solitária..."

426 NARA: "Solitária??"

427 ISABEL: "Não! tava... tava... solitária quer dizer 'sozinha' então não tem nada a ver. (Escrevendo) tava... tava... tão triiiiste que os filhos dela só falavam..."

Figura 1 : fragmento do texto « Os treis todinhos e a dona sabor ».

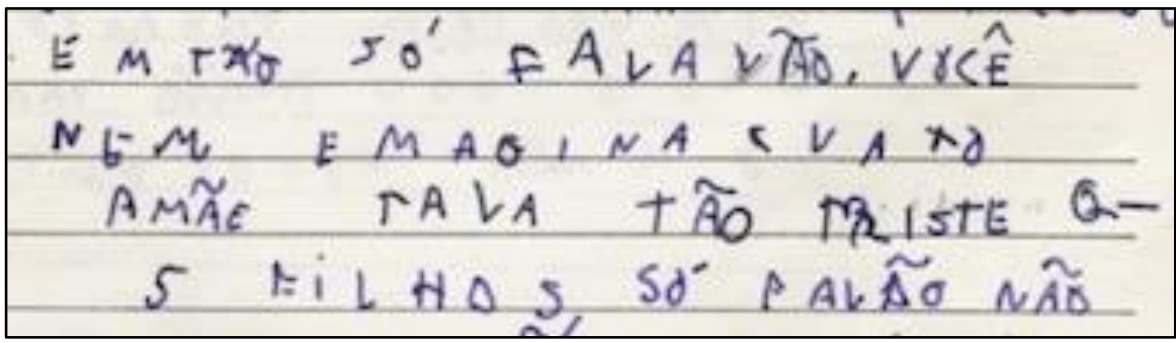

Fonte: Banco de dados do Laboratório do Manuscrito Escolar

No fragmento acima, Isabel propõe o termo « solitária » para descrever um estado (da mãe) que não correspondia ao esperado por Nara, que não apenas repete o termo, mas o faz com uma expressividade questionadora. A partir disso, Isabel é levada a responder a esse questionamento, refletindo sobre a utilização do termo e o sentido que elas pretendiam dar à história e propondo uma substituição do termo « solitária » pelo termo « triste ».

Como se vê, o falante, durante o processo de conversação, recorre a diversos artifícios que auxiliam na forma como a mensagem será interpretada pelo ouvinte. Ele seleciona o repertório mais adequado para cada tipo de situação e a forma como esse repertório será pronunciado, uma vez que a pronúncia pode despertar diversas reações em quem ouve, e é nesse contexto que a entonação entra em cena.

Baummen \& Grice (2007), ao tratarem sobre os atos comunicativos ilocutórios, ou seja, atos de fala que carregam uma intenção do falante, apontam quatro categorias principais: constativos (declarações), diretivos (perguntas, pedidos), comissivos (promessas) e reconhecimentos (desculpas). Nestes casos, a entonação tem papel fundamental na distinção de cada um. A entonação corrobora para a interpretação de estados subjetivos de ordem emocional do falante, exteriorizando sentimentos como raiva, tristeza, alegria, além de questões de ordem intelectual, como ignorância, dúvida, opinião, certeza, entre outros, como demonstram Aguiar \& Medeiro (2007). Ainda segundo os autores:

A entoação dá a uma palavra ou grupo de palavras, a marca da frase. As alterações da afetividade se refletem na linha musical da elocução e são percebidas pelo ouvinte. Involuntariamente, são extravasados pela melodia das palavras sentimentos reprimidos ou ocultos (2007, p. 229).

Com o desenvolvimento dos estudos da linguagem, entende-se que a entonação é um importante elemento do discurso oral, imprimindo à enunciação significações diferentes, e, além da possibilidade de favorecer o sucesso da interação, a entonação é muito importante na construção de sentido do discurso (AGUIAR \& MEDEIRO, 2007).

Moraes (1982), com base no trabalho de F. Danes, aponta as múltiplas funções da entonação: comunicativa; organizadora da mensagem em tema e rema; gramatical ou lexical; e modal 
subsidiária, expressiva. Esta última foi identificada nos processos analisados, pois ela se manifesta ao se reconhecer a atitude do falante no momento da interação conversacional, que podem provocar efeitos em quem ouve. Assim, é interessante destacar que a entonação expressiva, quando utilizada pelo falante, busca marcar determinado posicionamento no diálogo, porém, no caso específico deste trabalho, sua eficácia está no fato de ela aparecer articulada com a repetição, o que reforça ainda mais o posicionamento do aluno em relação ao que está sendo escrito, podendo gerar os apagamentos ao longo do processo, as rasuras orais.

O fragmento exposto mais acima também nos leva a pensar no papel da escrita colaborativa, pois trata-se de uma situação didática na qual dois ou mais participantes assumem a tarefa de escrever um único texto conjuntamente através do diálogo, o que torna o ambiente profícuo à produção de rasuras produzidas pela entonação e repetição. A escrita colaborativa também foi a forma encontrada para acessar o processo de escritura em tempo real. $\mathrm{Na}$ parte que segue, então, falaremos sobre ela e descreveremos a metodologia utilizada neste trabalho.

\section{A escrita colaborativa como ferramenta didática e como metodologia de coleta de dados}

Como ferramenta didática, a escrita colaborativa é uma atividade que proporciona aos envolvidos uma troca de conhecimentos, uma vez que durante a escritura de um texto os alunos costumam se deparar com questões que exigem posicionamentos, explicitações, argumentação, entre outros fatores que podem proporcionar aprendizado. Além disso, a interação com o parceiro pode resultar em reflexões e correções sobre a língua escrita, como pode ser percebido no texto dialogal dos nossos dados:

\section{Nara: "- (apontando a palavra 'ves') É 's' por acaso?"}

Isabel: "- Ah! (fazendo do 's' um ' $z$ ')"

É interessante destacar que durante o processo de escritura os alunos não se limitam a correções da ortografia, uma vez que eles também discutem sobre o conteúdo do texto, expressões linguísticas, entre outras questões que exigem a atenção e a interação dos sujeitos para que a atividade seja realizada adequadamente (BARBEIRO, 2007).

Murray (1992) ao tratar sobre a escrita colaborativa em grupo, afirma que para que uma atividade possa ser realizada com sucesso é interessante que os alunos tenham um objeto comum que irá orientá-los a realizar a tarefa de maneira eficaz. Ainda de acordo com a autora, é interessante que os alunos envolvidos possuam conhecimentos diferentes, pois isso facilitará a autenticidade da comunicação, estimulando a negociação de questões relacionadas ao texto. Assim, o fato de os alunos possuírem conhecimentos diferenciados contribui para que um busque apoio no outro, solicitando as informações necessárias para que juntos construam o seu conhecimento. Na escrita a dois não é diferente, pois elaborar um texto em colaboração exige dos sujeitos uma troca, além disso, cada aluno traz consigo uma bagagem diferenciada. Corroborando com esta questão, Barbeiro (2007, p. 111) afirma que:

\footnotetext{
A escrita colaborativa, na modalidade de realização conjunta e em co-presença de uma tarefa de escrita, coloca em interação sujeitos diferenciados, com níveis de competências diversos em relação à escrita, incluindo os níveis de competência ortográfica. A interação que tem lugar orienta-se para a necessidade de dar resposta à diversidade de problemas encontrados no processo, entre eles, a geração de conteúdo, a organização textual, a formulação linguística e a respectiva adequação e correção.
}

De acordo com Storch \& Wigglesworth (2009), quando aliado a uma didática eficaz, o trabalho em pares ou em grupos pode ter vários benefícios. No estudo realizado pelas autoras, em que participaram da investigação 144 voluntários, dos quais 96 escreveram em pares e 48

Revista do GELNE, Natal/RN, Vol. 20 - Número 1: p. 74-86. 2018 
individualmente, foi observado que os textos escritos em dupla são mais precisos, no que se refere ao tema abordado, quando comparados aos textos produzidos individualmente. Ademais, as investigadoras chegaram à conclusão que trabalhar em par proporciona oportunidades de aprendizagem.

A escrita colaborativa possibilita aos envolvidos o desenvolvimento de habilidades discursivas e argumentativas. Por essa razão, alguns pesquisadores defendem os trabalhos realizados em situações de interação, uma vez que, esse tipo de didática fornece informações importantes para um bom desempenho de trabalho em sala de aula. Os alunos envolvidos apreendem que existem pensamentos diferentes dos seus que possibilitam a troca de novas ideias e reconsiderações de respostas, podendo levar, também, a reformulação, ou seja, o aprimoramento a partir da troca de conhecimentos (LEAL \& LUZ, 2001). Também nessa perspectiva, Barbeiro e Pereira (2007, p. 10) mencionam que:

\begin{abstract}
A interação que ocorre na escrita colaborativa permite apresentar propostas, obter reações, confrontar opiniões, procurar alternativas, solicitar explicações, apresentar argumentos, tomar decisões em conjunto. Quando ocorre entre pares, permite colocar em relação, no interior do processo de escrita, alunos com desempenhos diferenciados, o que possibilita a observação da forma como os companheiros resolvem os problemas que vão surgindo.
\end{abstract}

Como metodologia de coleta de dados, a escrita colaborativa aliada a alguns dispositivos tecnológicos permite acesso ao processo de escrita, a partir do diálogo estabelecido pelos alunos. No caso do corpus aqui analisado, ele foi obtido a partir da filmagem e transcrição de processos de escrita, permitindo a análise do vídeo, do áudio, da transcrição e do próprio manuscrito. Para a presente pesquisa foram analisados 18 processos de uma díade recém-alfabetizada (Isabel e Nara ${ }^{5}$ ) da Escola da Vila, da rede particular da cidade de São Paulo-SP, no período de junho de 1991 a novembro de 1992, compreendendo $1^{\circ}$ e $2^{\circ}$ anos do Ensino Fundamental. O corpus faz parte do banco de dados Prática de Textualização na Escola (PTE), pertencente ao Laboratório do Manuscrito Escolar (L'ÂME), ambos são coordenados pelo pesquisador Eduardo Calil.

Em cada um dos 18 momentos, as alunas foram solicitadas, oralmente pelo professor, a combinar histórias inventadas por elas mesmas. Após o momento de combinação, uma folha de papel e uma caneta foram entregues e elas começam a escrever a história, durante cerca de uma hora. No processo, cada aluno tem uma tarefa específica, enquanto um fica encarregado de escrever, o outro fica responsável por ditar e ajudar o colega, de modo que, a cada processo os papéis são invertidos. Evidentemente, durante a escritura há várias interferências, e nem sempre o aluno incumbido por escrever é responsável por todas as marcas do texto, pois há momentos em que o ditante toma a caneta e produz uma rasura ou passa a escrever. Mais uma vez, esse fatos só podem ser observados porque temos acesso ao processo.

Para identificar as rasuras orais produzidas pela entonação, analisamos as 18 transcrições e seus respectivos processos. É possível identificar as rasuras através da transcrição, porém, em casos específicos temos que recorrer à filmagem para esclarecer eventuais dúvidas, principalmente pelo fato de estarmos trabalhando com a entonação.

A tabela a seguir mostra os dados analisados e o responsável por escrever a história. Utilizamos as iniciais dos nomes das alunas, assim I corresponde a Isabel e $\mathrm{N}$ a Nara. Como pode ser observado, por estar mais avançada no processo de alfabetização, Isabel escreveu a maioria dos textos:

${ }^{5}$ Para a pesquisa, mantivemos os nomes originais das alunas. 
Tabela 1: Rasuras orais da díade Isabel e Nara em 18 processos de escrita 1991 -1992

\begin{tabular}{lll}
\hline Título da história & $\begin{array}{l}\text { Responsável por } \\
\text { escrever }\end{array}$ & $\begin{array}{l}\text { Número de rasuras } \\
\text { orais }\end{array}$ \\
\hline A madrasta e as duas irmãs & I & 2 \\
As duas irmãs & N & - \\
A rainha comilona & I & - \\
A menina dos olhos azuis & I & - \\
Os três todinhos e a dona sabor & I & 2 \\
Um fim de semana atrapalhado & N & - \\
A princesa e a pedra encantada & I & 1 \\
O guarda roupa mágico & I & 2 \\
Capitão feio contra-ataca & N & 1 \\
O pequeno vampiro & I & - \\
Uma casa na floresta & N & - \\
Menina espolete & N & - \\
Saco & I & - \\
João contra os meninos da rua & I & - \\
A mãe má & I & 5 \\
A família F atrapalhada & N & 1 \\
Pedro e seus pensamentos & I & 3 \\
Os três irmãos & N & 1 \\
TOTAL DE RASURAS & - & 18 \\
\hline
\end{tabular}

Através da tabela, podemos perceber que as rasuras orais não foram identificadas em todos os processos, fator que pode estar relacionado à interação ${ }^{6}$, pois nos processos que apresentam mais discussões entre as alunas foram identificados um número maior de rasuras orais provocadas pela repetição e entonação.

\section{Dialogando com os dados}

Para tratarmos da questão proposta neste estudo, qual seja, a relação entre repetição e entonação na produção de rasuras, selecionamos um processo de escritura em que se pode observar várias repetições da fala do parceiro e os efeitos dessas repetições sobre o próprio locutor. Ao ditar o início da história, Nara questiona uma certa regularidade, uma forma muito comum de início de histórias, que é « era uma vez...» :

TD_ $7^{\circ}$ processo (manuscrito "A princesa e a pedra encantada") - 26/02/92

25 ISABEL: Era uma vez um...

26 NARA: A gente tem que escrevê 'era uma vez'?

27 ISABEL: E... é... um príncipe? Era uma vez um princípe e uma rainha..."

28 NARA: Era um dia... era uma vez um dia... muito bonito...

29 ISABEL: "- (RINDO) 'Era uma vez um dia!'... ahhh, vai, Nara...

30 NARA: É... vai...

31 ISABEL: (RINDO) Ô Nara... 'era uma vez um dia muito bonito’? Ô Nara? Que que é isso?

${ }^{6}$ Não podemos afirmar que a interação está diretamente relacionada à ausência de rasuras orais, provocadas pela repetição e entonação, em alguns processos. Porém, podemos apontar que a qualidade da interação é um fator essencial para os trabalhos que investigam o processo de escritura.

Revista do GELNE, Natal/RN, Vol. 20 - Número 1: p. 74-86. 2018 
32 NARA: Era uma vez um princípe que morava...

33 ISABEL: Um princípe e uma princesa e um rei que morava num castelo... [era uma ves um].

Ao tentar se desvencilhar da forma canônica « era uma vez », Nara propõe, no turno 28, « era um dia », mas resvala novamente no « era uma vez » ao dizer, neste mesmo turno, " era uma vez um dia ». Isabel, por sua vez, toma a fala de Nara para si repetindo-a nos turnos 29 e $31 \mathrm{com}$ uma entonação de deboche : «'Era uma vez um dia' !... ahhh, vai Nara » (turno 29) e " Ô Nara... “era uma vez um dia muito bonito’? ? (turno 31).

Como pode ser observado, a questão é de ordem textual, pois observamos que há uma insatisfação por parte de Isabel em iniciar a história com "era uma vez um dia muito bonito". Por trás dos enunciados proferidos por Isabel nos turnos 29 e 31 há uma recusa que não é exposta através de uma discussão propriamente. Para demonstrar seu posicionamento, a aluna provoca na parceira uma tensão através da retomada de suas próprias palavras. Desse modo, corroborando com o pensamento de Aguiar e Medeiro (2007), as intenções do falante se refletem, muitas vezes, na linha musical da elocução, fazendo com que o ouvinte perceba sentimentos que são extravasados através da melodia da fala. Assim, além de utilizar a entonação para demonstrar seu desacordo, Isabel utiliza a repetição das palavras de Nara como uma ferramenta intensificadora.

Embora no fragmento-exemplo situado mais atrás ("Solitária ? ») o objeto textual incida sobre uma única palavra e no fragmento acima ele repouse sobre uma frase inteira, os dois suscitaram rasuras orais, porém de formas diferentes. O primeiro, antes do pagamento, gerou uma reflexão em relação ao sentido da palavra, já o segundo gerou uma concordância, a desistência de uma ideia por outra.

A união da repetição com a entonação nos possibilita compreender o porquê de autores como Silva (2007) afirmarem que o ato enunciativo é irrepetível, pois as palavras podem ser as mesmas sintaticamente, mas o sentido é alterado, uma vez que o momento da enunciação não é o mesmo. Desse modo, Calil (2012), ao discutir sobre as características da rasura oral, afirma que sua caracterização principal está no retorno imprevisível sobre o enunciado proferido imediatamente, ou seja, ela é processual, ocorre no aqui e agora, no momento em que a díade está discutindo acerca do que vai ou não para o papel. Além disso, outra característica importante e que afasta ainda mais a rasura oral da reformulação é que, uma vez rasurado, os alunos seguem o curso da história sem discutir ou voltar ao ponto de tensão. Esse fato pode ser evidenciado a partir da continuação da discussão, no turno 32, em que Nara altera sua ideia inicial para "era uma vez um príncipe que morava..." e Isabel, alterando mais uma vez, acrescenta "um principe e uma princesa e um rei que morava num castelo". Mais uma vez, se observássemos apenas o manuscrito final, não teríamos acesso a toda a discussão que desencadeou o desabrochar da história, visto que as alunas não deixaram marcas, como pode ser observado no recorte do manuscrito:

Figura 2 - Estado do manuscrito escolar "A princesa e a pedra encantada"

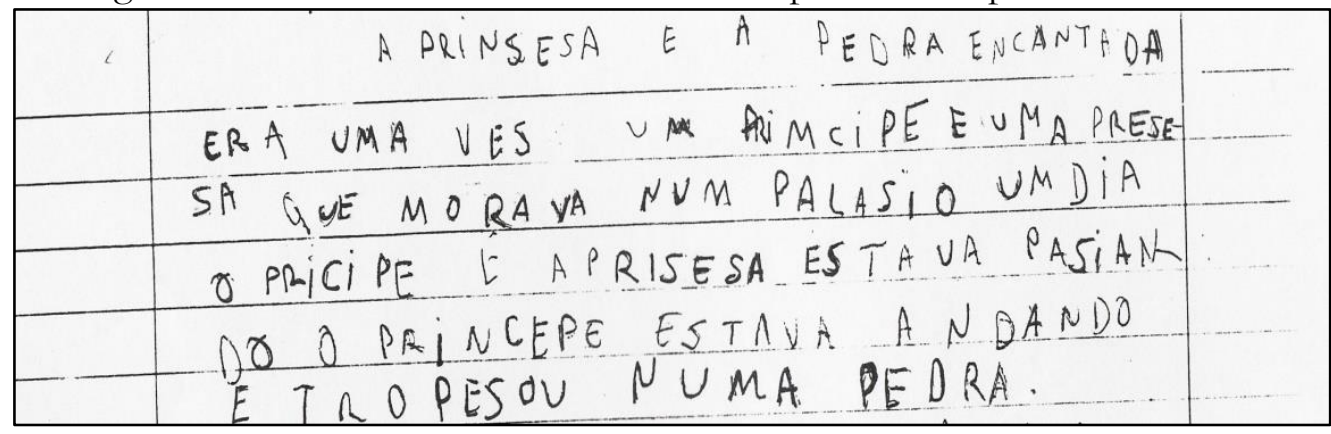

Fonte: Banco de dados do Laboratório do Manuscrito Escolar 


\section{CONSIDERAÇÕES FINAIS}

Durante o trabalho, buscou-se mostrar, através de uma metodologia específica de coleta de dados, que o processo de escrita carrega consigo uma série de fenômenos e especificidades que merecem atenção. Entre esses fenômenos, a rasura oral é o ponto central desta investigação. Para discutir sobre esse elemento inerente ao ato de escrita colaborativa, foi necessário recorrer aos aportes de duas áreas do conhecimento : Linguística da Enunciação e Genética de Textos.

A primeira possibilita a compreensão das relações estabelecidas durante a instauração do ato enunciativo. A segunda aponta discussões interessantes acerca da gênese do texto, apresentando os conceitos de rasura e manuscrito, elementos imprescindíveis para este trabalho. Também, apresentou-se, ao longo da discussão, os aportes teóricos sobre repetição, por ser um elemento essencial e recorrenre nos processos analisados, e aos estudos sobre entonação, por ser o elemento responsável por alterar a melodia das palavras, fazendo com que, aquilo que parece ser igual, do ponto de vista lexical, seja diferente aos ouvidos do locutor.

Assim, observa-se que é na instância do discurso que a rasura oral entra em ação, ela ocorre porque durante todo processo há uma interlocução $e u-t u$, que se evidencia através das sobreposições de ideias, indagações, argumentações, incertezas, dúvidas, entre outras, explicitadas pelas alunas no momento de composição do texto. Desse modo, o espaço e o tempo se destacam, pois a rasura oral ocorre no aqui e agora, no momento da enunciação. Sendo assim, observar como a articulação entre repetição e entonação pode gerar tensões durante as discussões, no texto em curso, e como essas tensões repercutem em apagamentos ao longo do processo, é um passo importante para compreender esse fenômeno (rasura oral) e contribuir para os estudos que se debruçam sobre o processo de escrita, com todas as suas especificidades, e não apenas sobre o produto final. Ademais, não se pode deixar de pontuar a relevância do estudo para uma didática da escrita, visto que, analisar o processo de escritura de um texto em colaboração, proporciona a observação das reflexões que os alunos fazem sobre a escrita, os ganhos advindos destas reflexões e a consciência linguística que é adquirida, pelos alunos, a partir da prática e da relação de aprendizagem que se estabelece quando juntos eles têm que realizar a tarefa de escrever um texto.

\section{REFERÊNCIAS BIBLIOGRÁFICAS}

AGUIAR, Marígia; MADEIRO, Francisco. Em-TOM-Ação: a prosódia em perspectiva. Recife : Editora Universitária UFPE, 2007.

BAUMANN, Stefan; GRICE, Martine. "An Introduction to Intonation - Functions and Models," In: Non-native Prosody: Phonetic Description and Teaching Practice, Trouvain, J. and Ulrike, G. (eds), pp. 25-52, Mouton de Gruyter, 2007.

BIASI, Pierre-Marc de. Análise dos manuscritos: princípios e métodos. In: BIASI, Pierre-Marc de. A genética dos textos. Tradução Marie-Hélène Paret Passos. Porto Alegre: EDIPUCRS, 2010.

BENVENISTE, Émile. Problemas de Linguística Geral I. $3^{\text {a }}$ ed. Campinas, SP: Pontes: Editora da Universidade Estadual de Campinas, 1991.

BENVENISTE, Émile. Problemas de Linguística II. $2^{a}$ ed. Campinas, SP: Pontes Editores, 2006. 
BARBEIRO, Luís Felipe. Episódios ortográficos na escrita colaborativa. XXII Encontro Nacional da Associação Portuguesa de Linguística, Lisboa: APL, 2007, pp. 111-125.

BARBEIRO, Luís Felipe ; PEREIRA, Luísa Alves. O ensino da escrita: a dimensão textual. Ministério da Educação: Lisboa, 2007.

CALIL, Eduardo. Rasuras orais em madrasta e as duas irmãs: processo de escritura de uma díade recém-alfabetizada. Educação e Pesquisa (online). vol. 38, n 3, jul/set. 2012. Disponível em: http://www.scielo.br/pdf/ep/v38n3/aop389.pdf

CALIL, Eduardo. O sentido das palavras e como eles se relacionam com o texto em curso: estudo sobre comentários semânticos feitos por uma díade de alunos de 7 anos de idade. Alfa, São Paulo, 60 (3): 531-555, 2016.

DESHAIES, Denise; PARADIS, Claude; PERRIN, Laurent. Pragmatic functions of local diaphonic repetitions in conversation. Journal of Pragmatics. n 35, jun. 2003.

GAULMYN, M.-M. de.; BOUCHARD, R.; RABATEL, Al. (Éd.). Le processus rédactionnel: écrire à plusieurs voix. Paris: L' Harmattan, 2001.

GRÉSILLON, Almuth. Elementos de crítica genética: ler os manuscritos modernos. Porto Alegre: Editora da UFRGS, 2007.

$\mathrm{KOCH}, \mathrm{I}$. Villaça. A repetição na língua falada como estratégia de formulação textual. In. KOCH, I. Villaça. (Org.) Gramática do Português Falado. Desenvolvimentos. Vol. VI. $2^{a}$ ed. São Paulo: UNICAMP, 2002.

LEAL, Telma Ferraz \& LUZ, Patrícia Santos. Produção de textos narrativos em pares: reflexões sobre o processo de interação. In: Educação e Pesquisa (online). vol. 27, n1, jan/jun. 2001. Disponível em: http://www.anped.org.br/reunioes/23/textos/1010t.PDF. Acesso em: 20 de fev. 2013.

MARCUSCHI, Luiz Antônio. Repetição. In: JUBRAN, Clélia Cândida A. Spinardi; KOCH, Ingedore G. Villaça (Org.). Gramática do português falado no Brasil: construção do texto falado. São Paulo: contexto, 2015, v.1. p. 207 - 240.

MORAES, João Antônio. Em torno da entoação: alguns problemas teóricos. Cultura Linguística, n. 1, p. 63-78, 1982.

MURRAY, Denise E. Collaborative writing as a literacy event: implications for ESL instruction. In: David Nunan (ed.): Collaborative Language Learning and Teaching. Cambridge: CUP, 1992.

SILVA, Carmem Luci da Costa. A instauração da criança na linguagem: princípios para uma teoria enunciativa em aquisição da linguagem. 2007. 293f. Tese (Doutorado em Linguística) Instituto de Letras da UFRS. Universidade Federal do Rio Grande do Sul, Rio Grande do Sul.

STORCH, Neomy \& WIGGLESWORTH, Gillian. Pair versus individual writing: Effects on fluency, complexity and accuracy. In: Language Testing, 26 (3), p. 445-466, 2009.

TANNEN, Deborah. Talking voices: repetition, dialogue, and imagery in conversational discourse. 2 Ed. Cambridge University Press, 2007. 
WILLEMART, Philippe. Do manuscrito ao pensamento pela rasura. Revista Manuscrita, n. 7, p 21-35, 1995.

WILLEMART, Philippe. Universo da Criação Literária: crítica genética, crítica pós-moderna? São Paulo: Editora da Universidade de São Paulo, 1993.

Recebido em 22/1/2018

Aceito em 2/4/2018 